\title{
Anti-reflux mucosectomy with band ligation in the treatment of refractory gastroesophageal reflux disease
}

For patients with refractory gastroesophageal reflux disease (rGERD), the American Society for Gastrointestinal Endoscopy recommends surgical treatment such as fundoplication to reduce the diameter of the cardia [1]. Several endoscopic treatments are described using new devices, but they suffer from a lack of feasibility and high costs [2]. Anti-reflux mucosectomy (ARMS) could also narrow the esophagogastric junction (EGJ) as a result of tissue shrinkage induced during cicatrization $[3,4]$. We applied this technique using band ligation (ARMS-b) in the management of rGERD.

We report the case of a 63-year-old man with a long history of GERD uncontrolled by proton pump inhibitor (PPI) therapy. His main symptom was daily pyrosis, which had a significant impact on his quality of life. The diagnosis was confirmed by $\mathrm{pH}$-impedancemetry and manometry, which eliminated an esophageal motility disorder. ARMS-b was performed in this patient in an ambulatory setting.

For the ARMS-b procedure, a Duette Band Ligation device (Cook Medical, Bloomington, Indiana, USA) was mounted onto an endoscope with large operating channel $(3.8 \mathrm{~mm})$. Adrenaline serum (1/1000) was injected into the submucosa at the EGJ oriented toward the lesser curvature of the stomach. The mucosa was captured with the band ligation device, and piecemeal mucosectomy of three-quarters of the circumference of the EG] was performed using a hexagonal snare (ERBE VIO2 settings: Endocut Q, effect 2) ( $\triangleright$ Fig. 1, $\triangleright$ Video 1). The patient was discharged on a mixed diet for 5 days and maximum dose PPI therapy twice daily for 2 months

There was no perioperative complication. The endoscopic follow-up at 3 months showed cicatrization of the EG] and a narrowing of the cardia with an "anti-reflux valve" effect seen in retroflexion ( $\triangleright$ Fig. 2). Pyrosis had totally disappeared at 1 month. At 1-year followup, there was no recurrence of pyrosis and the $\mathrm{pH}$-impedancemetry value had returned to normal.

This case suggests that ARMS-b can achieve good control of the main symptom of rGERD. The procedure seems reproducible, safe, and feasible in the ambulatory setting. Further studies are required to confirm this promising outcome.

Endoscopy_UCTN_Code_TTT_1AO_2AJ

Competing interests

None



- Fig. 1 Procedure for anti-reflux mucosectomy with band ligation. a Injection of adrenaline serum into the submucosa of the esophagogastric junction (EG]). b Capture of mucosa with the band ligation device. c Mucosectomy of the mucosa using a hexagonal snare. $\mathbf{d}$ Final result of piecemeal mucosectomy of three-quarters of the circumference of the EGJ, oriented toward the lesser curvature of the stomach.

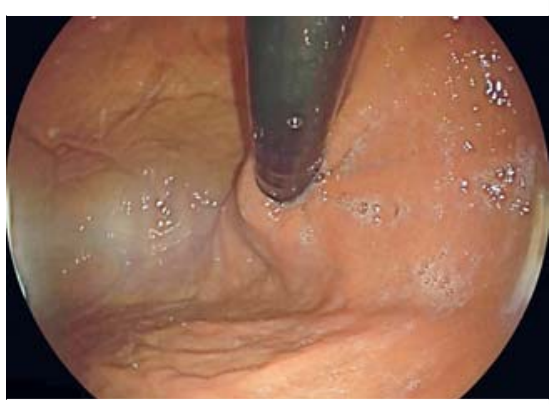

- Fig. 2 "Antireflux valve" effect of the esophagogastric junction in retroflexion. 


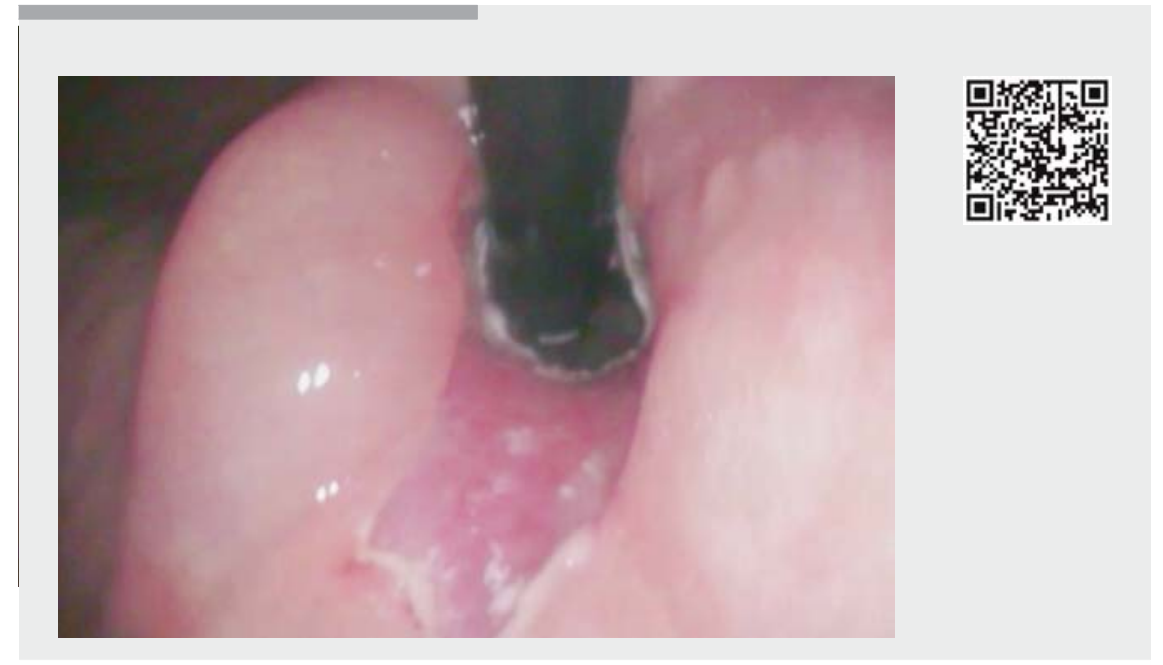

Video 1 Anti-reflux mucosectomy with band ligation. The steps - submucosal injection, mucosal capture with band ligation, and mucosectomy - were performed three times until resection of three-quarters of the circumference of the esophagogastric junction (EGJ). After cicatrization of the EGJ, an "antireflux valve" effect was seen in retroflexion.

Laurent Monino ${ }^{1,2}$, Jean-Michel Gonzalez ${ }^{2}$, Veronique Vitton ${ }^{2}$, Marc Barthet ${ }^{2}$

1 Department of Hepatogastroenterology, Université Catholique de Louvain, Cliniques Universitaires Saint-Luc, Brussels, Belgium

2 Department of Hepatogastroenterology, Assistance Publique des Hôpitaux de Marseille, Aix-Marseille Université, Hôpital Nord, Marseille, France.

\section{Corresponding author}

\section{Laurent Monino, MD}

Department of Hepatogastroenterology, AP-HM, Aix-Marseille Université, Hôpital Nord, Chemin des Bourrely, 13015 Marseille, France

Fax: +33-4-91968737

laurent.monino@uclouvain.be
[1] Katz PO, Gerson LB, Vela MF. Guidelines for the diagnosis and management of gastroesophageal reflux disease. Am J Gastroenterol 2013; 108: $308-328$

[2] Pearl J, Pauli E, Dunkin B et al. SAGES endoluminal treatments for GERD. Surg EndosC 2017; $31: 3783-3790$

[3] Inoue $\mathrm{H}$, Ito $\mathrm{H}$, Ikeda $\mathrm{H}$ et al. Anti-reflux mucosectomy for gastroesophageal reflux disease in the absence of hiatus hernia: a pilot study. Ann Gastroenterol 2014; 27: 346 351

[4] Eleftheriadis N. Endoscopic treatment of GERD and case report: successful anti-reflux mucosectomy (ARMS) for endoscopic treatment of PPI-resistant GERD in a 24-years-old Greek. Adv Res Gastroenterol Hepatol 2017; 3: 555602

\section{Bibliography}

DOI https://doi.org/10.1055/a-0875-3479

Published online: 30.4.2019

Endoscopy 2019; 51: E215-E216

(c) Georg Thieme Verlag KG

Stuttgart · New York

ISSN 0013-726X

\section{ENDOSCOPY E-VIDEOS \\ https://eref.thieme.de/e-videos}

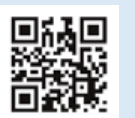

Endoscopy E-Videos is a free access online section, reporting on interesting cases and new techniques in gastroenterological endoscopy. All papers include a high quality video and all contributions are freely accessible online.

This section has its own submission website at https://mc.manuscriptcentral.com/e-videos 